\title{
Dos textos en árabe dialectal de Damasco
}

\author{
Two texts in the dialectal Arabic of Damascus
}

\author{
Carmen BERLINCHES RAMOS \\ Doctoranda en el Dpto. de Estudios Árabes e Islámicos \\ Becaria MAEC-AECID / Institut français du Proche-Orient (IFPO), Damasco. \\ Universidad Complutense de Madrid \\ carmenberlin81@yahoo.es
}

Recibido: octubre 2010

Aceptado: noviembre 2010

\section{RESUMEN}

Este artículo presenta dos textos en árabe dialectal de Damasco (Siria) con su correspondiente análisis y traducción al español. Con ello se pretende reflejar algunas de las principales características del habla actual de los jóvenes damascenos.

Palabras clave: Dialectología árabe. Dialectos orientales. Dialecto de Damasco.

\section{ABSTRACT}

This paper contains two texts in the dialectal Arabic of Damascus (Syria), followed by an analysis and the Spanish translation thereof. The aim is to show the main characteristics of the modern language spoken amongst the young Damascenes.

Key words: Arabic dialectology. Oriental dialects. Dialect of Damascus.

ÍNDICE: 1. Introducción. 2. Signos usados en la transcripción fonológica. 3. Textos. 


\section{INTRODUCCIÓN}

El propósito del presente artículo es realizar una pequeña aportación para el estudio de los dialectos de la región siro-libanesa, en concreto del actual dialecto de Damasco, con ese fin presento dos textos pertenecientes a dos jóvenes nacidas y criadas en la capital siria. La primera es Rīm Rāšed, nacida en 1981 y estudiante de Filología Inglesa en la Universidad de Damasco, la segunda es Nūr YAzziz, nacida en 1983, licenciada en Filología Inglesa y estudiante de un Máster en Recursos Humanos. Las grabaciones fueron realizadas en Damasco en el mes de noviembre de 2007.

El interés por el dialecto hablado por la población joven se debe en primer lugar a que dicho dialecto está sufriendo una constante y rápida evolución ya que actualmente la gran mayoría de los jóvenes damascenos estudian diferentes idiomas (inglés, francés y en menor medida español ${ }^{1}$ ) y se encuentran profundamente influidos por diversos medios de comunicación, principalmente la televisión y el internet, a partir de los cuales tienen acceso al mundo exterior y con él a otras lenguas. Por otro lado, los escasos estudios existentes en lengua española sobre este dialecto, más concretamente del sector más joven, agudizan la necesidad de realizar nuevos trabajos que reflejen los cambios y las nuevas aportaciones al dialecto local.

La elección de los textos no ha sido aleatoria. En el primero una joven explica por qué lleva hijāb, por lo que el vocabulario presenta algunos términos más cercanos al árabe clásico y el registro es un tanto más elevado. En el segundo encontramos a una joven que nos habla de la moda en Siria, aportando numerosos préstamos, expresiones nuevas y utilizando un registro más informal. Con ellos también pretendo reflejar la diversidad social que existe en la capital siria.

El lenguaje de los textos es oral y las informantes hablaron con total naturalidad sin realizar una preparación previa. He intentado conservar una traducción fiel de los textos ${ }^{2}$ pero debido a la naturaleza de los mismos, dicha traducción puede contener muchas repeticiones y e incluso resultar incoherente en algunas ocasiones.

\footnotetext{
${ }^{1}$ Desde 2007 existe en la Universidad de Damasco la licenciatura de Filología Española y el número de estudiantes es cada vez más elevado, actualmente cuenta con un número aproximado de 200 alumnos (datos facilitados por Raúl Zayas, lector en la Universidad de Damasco). Además, el Instituto Cervantes cuenta con una gran cantidad de matrículas que en algunos periodos pueden llegar a superar los 600 alumnos.

${ }^{2}$ Para la traducción se han utilizado principalmente los siguientes diccionarios de árabe - español y árabe dialectal - español: BARTHÉLEMY, A. Dictionnaire arabe-français. (Dialectes de Syrie: Alep, Damas, Liban, Jérusalem). Paris. 1935, CORRIENTE, F y FERRANDO, I. Diccionario avanzado árabe. Barcelona. 2005, CORTÉS, J. Diccionario del árabe culto moderno. Madrid. 1996, FRAYHA, A. Dictionary of non classical vocables in the spoken Arabic of Lebanon. Beirut. $1947 \mathrm{y}$ STOWASSER, K. y MOUKHTAR, A. A Dictionary of Syrian Arabic (Dialect of Damascus) EnglishArabic. Washington. 1964.
} 


\section{SIGNOS USADOS EN LA TRANSCRIPCIÓN FONOLÓGICA}

Vocales:

/a/ (breve, abierta y central). /ā/ (larga, abierta y central). /e/ (breve, media y anterior). / $\mathrm{e} /$ (larga, media y anterior). /i/ (breve, cerrada y anterior). /1//(larga, cerrada y anterior). /o/ (breve, media y posterior). / $\overline{\mathbf{o}} /$ (larga, media y posterior). / $\mathrm{u} /$ (breve, cerrada y posterior). / $\mathrm{u} /$ (larga, cerrada y posterior). /a/ (breve, media y central). $/ \%$ (vocal anaptíctica, ultra breve).

Consonantes:

/'/ (glotal oclusiva sorda)./b/(bilabial oclusiva sonora). /t/ (dental oclusiva sorda). $/ \mathrm{j} /(\text { prepalatal fricativa sonora) })^{3}$. $/ \mathrm{h} / \quad$ (faringal fricativa sorda). $/ \mathrm{x} /$ (velar fricativa sorda). /d/ (dental oclusiva sonora). /r/ (alveolar vibrante sonora). /z/ (alveolar sibilante sonora). /s/ (alveolar sibilante sorda). /š/ (prepalatal africada sorda). /ș/ (alveolar sibilante sorda enfática). /ḍ/ (dental oclusiva sonora enfática). /ț/ (dental oclusiva sorda enfática). / $/$ / (alveolar sibilante sonora enfática) ${ }^{4}$. / $/$ / (faringal fricativa sonora). $/ \dot{\mathrm{g}} /$ (velar fricativa sonora). $/ \mathrm{g} /$ (postpalatal oclusiva sonora). /f/ (labiodental fricativa sorda). /q/ (faringal oclusiva sorda). /k/ (postpalatal oclusiva sorda). /1/ (alveolar lateral sonora). $/ \mathrm{m} /$ (bilabial nasal sonora). $/ \mathrm{n} /$ (dental nasal sonora). $/ \mathrm{h} /$ (glotal fricativa sorda). $/ \mathrm{w} /$ (semiconsonante bilabial fricativa sonora). $/ \mathrm{y} /$ (semiconsonante prepalatal fricativa sonora).

Entre corchetes y en español aparecen las preguntas realizadas por mí con el fin de no crear confusiones con el texto de las informantes.

\section{TEXTOS}

\subsection{TEXTO 1. "MI HIJĀB". RĪM RĀ ŠED}

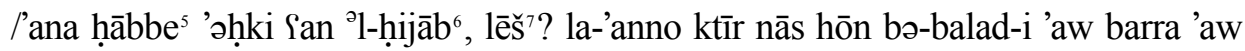

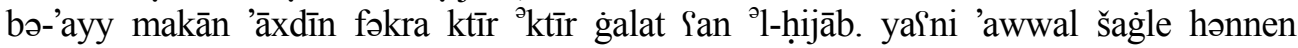

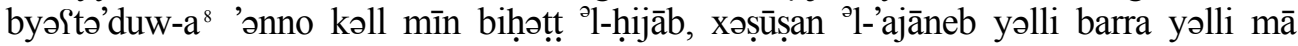

${ }^{3}$ La realización fricativa de la consonante africada / $\mathrm{g} /$ es característica de las poblaciones urbanas de Siria, Palestina y Jordania, según indica CANTINEAU, J. Cours de Phonétique Arabe. (Suivi de notions générales de Ponétique et de Phonologie. 1960, pág. 59.

${ }^{4}$ Según BARBOT, M. "Emprunts et phonologie dans les dialectes citadins syro-libanais", en Arabica 8, fasc. 2, (1961), pág.183, este nuevo fonema surge tras la desaparición del fonema clásico / $\mathrm{V} /$, por influencia de la lengua turca cuyos hablantes eran incapaz de pronunciarlo.

${ }^{5}$ Participio activo. En el dialecto de Damasco es muy frecuente el uso de participios activos con valor de verbo en presente.

${ }^{6}$ Se mantiene el sustantivo clásico al tratarse de una palabra religiosa. Su correspondiente dialectal hjā $b$, con pérdida de vocal en sílaba inicial, generalmente toma el significado de "amuleto".

${ }^{7}>l i+$ 'ayyi + šayinn.

${ }^{8}$ Realización de /q/ como / / (glotal, oclusiva, sorda), característica de los sedentarios. Sobre este fenómeno ver VICENTE, A. "Génesis y clasificación de los dialectos neoárabes", en Manual de dialectología neoárabe, (2008), pág. 57. 


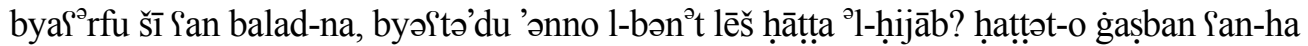

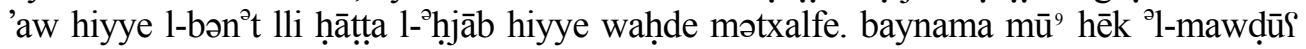
'abadan. huwwe 'awwal š̄i, 'awwal šag̉e, mū kəll 'l-banāt mahțūt gasban Sann-on ${ }^{10}$ yaini huwwe mū taqlīd"1 , huwwe mahtūt la-hadaf ${ }^{2}$ mfayyan. fi nās 'è, btəğșeb ${ }^{2}$ wlād-a 'onn-

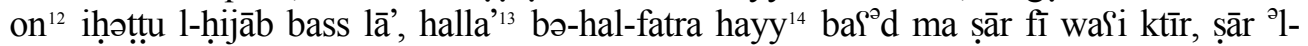

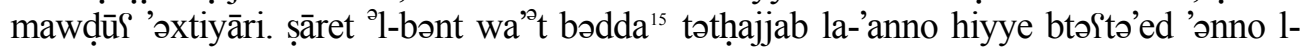

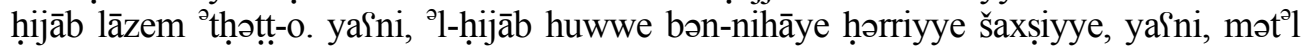
'ana xtər ${ }^{2} t$ 'ənno 'ana gatți hāda j-jəz' mən jəsm-i, yəlli huwwe rāsi, tamām? fi nās'

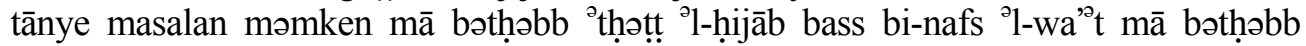

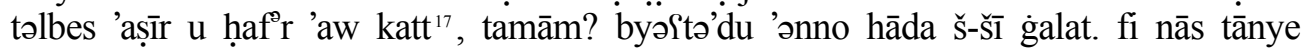

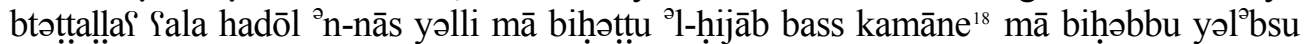
'awā̧i məl' fte lən-naẓar 'aw 'așīre 'aw hēk, byəStə’'du 'ənno hənnen mətxallfīn. țayyeb, fi

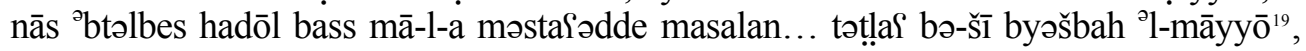
māši? Sat-țarî̀, māši? fi nās, țayyeb, məståədde ’ənno hənnen yəțla\{u, məståddīñ ${ }^{20}$ yəțlâu bəz-ẓal'ț, māši? law 'l-qānūn ${ }^{21}$ byəsmaḥ̂-l-on, bass hənnen la-'anno mā byəsmah-1-on fa-hənnen... yaini hənnen bən-nihāye mā btəfre' må-on.

${ }^{9}>m \bar{a}-h u>m \bar{a}$ huwwa. Según BARTHÉLEMY, A. Dictionnaire árabe..., pág. 805. Se utiliza en lugar del verbo clásico laysa.

${ }^{10}$ Pronombre sufijado para la tercera persona del plural masculino y femenino. El dialecto de Damasco se caracteriza por presentar los pronombres sufijados de plural únicos para ambos géneros. Por otro lado, destaca la geminación de /n/ que presenta la preposición San "a cerca de, sobre" que tiene lugar también en la preposición mon ( > min) "de, desde" y en la conjunción ’on "que", al ser sufijado un pronombre.

${ }^{11}$ Conservación de /q/ por tratarse de un préstamo del árabe clásico.

${ }^{12} \mathrm{~V}$. supra nota 10.

13 "Ahora" > hal-wa't "este momento". Presenta la asimilación /lw/ > /11/, según BARBOT, M. Évolution de l'Arabe contemporain. 2 vols. (Vol. I: Bibliographie d'Arabe moderne et du Levant. Introduction au parler de Damas. Vol. 2: Les sons du parler de Damas). Paris. 1981, pág, 503. Además se observa una pérdida de /t/ como consecuencia de la contracción de la palabra.

${ }^{14}$ Es común el uso de dos pronombres demostrativos, uno de ellos prefijado, para un mismo sustantivo, la traducción se realiza como si hubiera uno solo: bə-hal-fatra hayy "en esta época".

${ }^{15}$ El verbo dialectal bədd- (+ pronombre sufijado) "querer", procede del árabe clásico bi-widd-nā "nos gustaría" (lit. "en nuestro deseo") y ha sufrido una pérdida de /w/ excepcional en este dialecto, según indica BARBOT, M. Évolution..., pág. 503.

${ }^{16}$ El sustantivo nās "gente", es tratado en ocasiones como singular y en otras como plural, siendo más frecuente que sea considerado singular. En el texto tenemos un claro ejemplo de estos dos tratamientos: $f i$

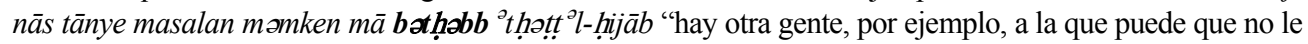

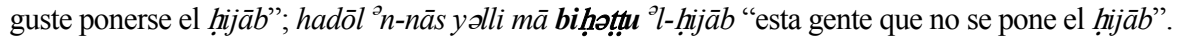

${ }^{17}$ Préstamo no integrado del inglés cut con el sentido de "corto".

18 “Todavía”. Variante de kamān > kamā +-ān. Según BARTHÉLEMY, A. Dictionnaire árabe..., pág. 727.

${ }^{19}$ Préstamo del francés maillot con el sentido de "traje de baño".

${ }^{20}$ V. supra nota 16.

${ }^{21}$ Los términos relacionados con el derecho son préstamos del árabe clásico en todos los dialectos árabes, tanto en los beduinos como en los sedentarios, por lo que encontramos que el sustantivo qānūn "ley" no presenta la pérdida de /q/ y además conserva la cantidad vocálica del árabe clásico. 


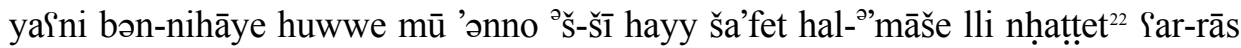
bə-zāt hiyye månāt-a ${ }^{23}$ şəfi 'ənno hāda l-’onsān mətxallef 'aw mū mətxallef, huwwe,

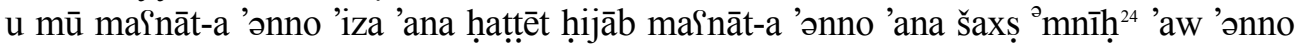

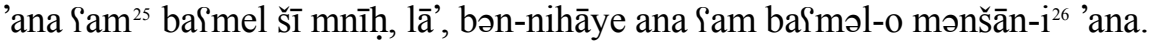

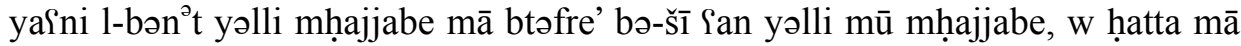

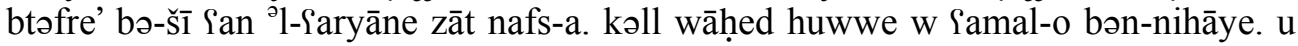

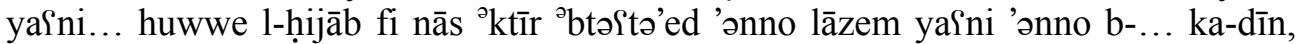

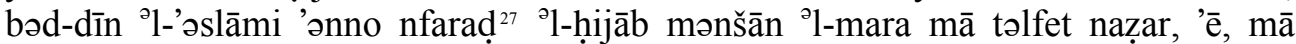
təlfet naz̧ar bass mənšān šū? mənšān hiyye təḥmi ḥāl-a, yâni... mənšān mā hadan

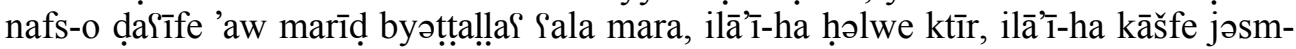
a... irūḥ huwwe mā byəḥsen ’onno ymāres 'ayy... imāres ${ }^{\circ} 1-$ sēkso $^{28}$ maf hadan, 'ē? 'aw bə-\{and-o rag̉be ’ənno yåmel hāda š-šî, byaimel sēkso maS hādan fa-məmken irūḥ u yə’ziy-a məmken irūḥ yəg்təșəb-a, tamām? 'ē... halla' 'l-wa't 'tg̉ayyar, māší? u fi nās bi'ūlu 'ē țayyeb, lēš mū r-rajjāl mā biḥoțt kamān '-hijāb? țayyeb, ma huwwe r-rjjāl, mā fiy-o šī byəlfet ${ }^{~}{ }^{1}$-nażar... bəl-nihāye dāiman ${ }^{~}{ }^{\circ}$ r-rəjjāl 'a'wa mn ${ }^{2} 1$ mara, yåni huwwe byəḥsen yəji w yəzī-ha ləl-mara, ${ }^{~} 1$-mara mā btəḥsen tåmel šî.

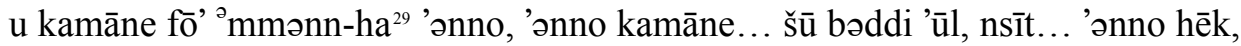

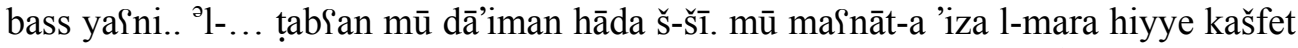

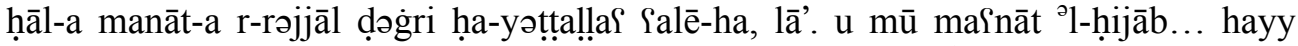
'ahamm 'ahamm šag̉le, 'ahamm nə’ṭa bəl-ḥijāb, mū månāt 'l-ḥijāb 'ənno l-waḥde tg̉atți šår-a bass, lā', 'iza hiyye kašfet šår-a bass gatțet kəll jəsm-a 'aw yåni ləbset

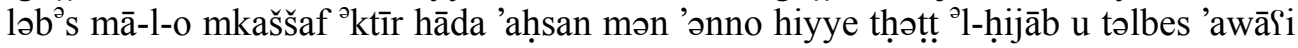

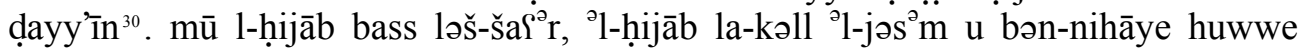

${ }^{22}$ Voz pasiva formada con el esquema de la forma verbal VII ${ }^{\mathrm{a}}$. La gran mayoría de los verbos dialectales en Damasco realizan la voz pasiva siguiendo dicho esquema.

${ }^{23}$ El sustantivo maSna "significado" de género masculino y perteneciente a la raíz defectiva $\{\mathrm{SNY}\}$, introduce una /-t/ (t $\bar{a}^{\prime}$ 'marbüta $)$, como si de una palabra femenina se tratara, cuando se le añade un sufijo, produciendo un fenómeno de ultracorrección. COWELL, M.W. A Reference Grammar of Syrian Arabic. Washington. 1964, págs. 165 y 169.

${ }^{24}$ Asimilación de $/ 1 /$ en $/ \mathrm{n} /$ por contacto con $/ \mathrm{m} /:$ malīh $>$ mnīḥ "bien". Sobre este punto ver BARBOT, M. Évolution..., pág. 387.

${ }^{25}$ Preverbio de acción actual o progresiva, según indica BEHNSTEDT P. "Árabe levantino”, en Manual de dialectología neoárabe, (2008), pág. 168. Sobre sus variantes y usos ver COWELL, M.W. A Reference..., pág. 320.

${ }^{26}>\min +\check{s} a$ 'an . Conjunción final "para que, con el fin de...”. Según DRIVER, G.R. A Grammar of the Colloquial Arabic of Syria and Palestine. Londres. 1925, pág. 203, nota 2, se trata de una preposición usada como conjunción.

${ }^{27}$ Voz pasiva.

${ }^{28}$ La informante hizo uso de la palabra en español, a modo de eufemismo, para evitar decirla en árabe clásico.

${ }^{29}$ Geminación de $/ \mathrm{m} /$ en la preposición mon "de, desde" atribuido según BARBOT, M. Évolution..., pág. 830, a la asimilación de un antiguo final adverbial /-an/.

${ }^{30}$ Uso del plural sano en /-īn/ con seres inanimados. 


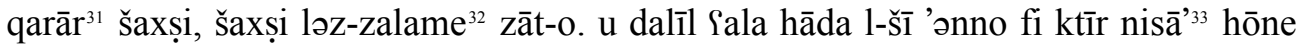
nəswān bə-balad-na nājḥīn ${ }^{34}{ }^{~} k$ ktīr hạatțīn ${ }^{\partial} 1$-ḥijāb... mū månāt-a 'ənno hənnen

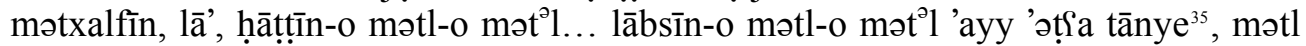

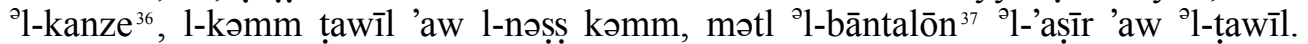
hayy hiyye bən-nihāye hiyye hə̣rriyye šaxșiyye.

wəl-bən't kamāne yəlli xtāret 'ənno hiyye mā tḥıțt hijāb hiyye kamān hayy ’əl-a hərriyye šaxṣiyye. yaini hayy mət ${ }^{2} 1$ hayy, bass/.

\subsection{TRADUCCIÓN}

Quiero hablar del hijāab, ¿por qué? Porque mucha gente aquí en mi país, o fuera o en cualquier lugar, ha adoptado una idea muy muy equivocada sobre el hijāb. Lo primero es que ellos consideran que toda la que lleva hija $\bar{b} b$, especialmente los extranjeros de fuera, que no saben nada de nuestro país, creen que la chica ipor qué se pone el hijāb? Se lo pone a la fuerza, o ella, la chica que se pone el hija $\bar{b} b$ es una retrasada. Mientras que el tema no es para nada así. Lo primero es que no todas las chicas se lo ponen a la fuerza, o sea, que no es tradición, se pone por un objetivo determinado. Hay gente que sí, que obliga a sus hijas a ponerse el hijāb, pero no, ahora, en esta época, después de que haya surgido mucha conciencia, el tema se ha convertido en opcional. La chica que quiere ponerse el hijāa $b$ es porque ella cree que tiene que ponérselo. O sea, el hijā $b$ al final, es una libertad personal, a ver, así como yo elegí cubrir esta parte de mi cuerpo que es la cabeza, ¿bien? hay otra gente que, por ejemplo, puede que no le guste ponerse el hijja $b$, pero al mismo tiempo no le gusta vestir de corto o sin mangas o corto isí? consideran que eso es un error. Hay otra gente que mira a esta gente que no se pone el hijāb pero que tampoco le gusta llevar ropa que llame la atención o corta o así, piensan que ellas son retrasadas. Bien, hay gente que lleva todo esto pero no está dispuesta, por ejemplo, a salir con algo parecido al bañador, ¿vale? por la calle ¿vale? hay gente, bien, dispuesta a salir desnuda, ¿vale? si la ley se lo permitiera, pero como no se le permite, pues... al final les da igual.

${ }^{31}$ V. supra nota 21.

${ }^{32}$ El sustantivo zalame "hombre", del árabe clásico zalmatu "apariencia, silueta de hombre", según BARTHÉLEMY, A. Dictionnaire árabe..., pág. 318, ha sido tomada de la lengua de los nómadas. A pesar de que termina en vocal/-e/, es masculino y no existe su forma femenina.

${ }^{33}$ La informante emplea este plural clásico del sustantivo mara "mujer", e inmediatamente después utiliza el plural dialectal nəswān.

${ }^{34}$ Los plurales femeninos de los participios desaparecen en el dialecto, realizándose todos en /-īn/.

${ }^{35}$ Pérdida de la interdentalidad o conversión de las consonantes interdentales en las dentales correspondientes, característica de los dialectos sedentarios. Sobre este punto ver BARBOT, M. "Emprunts...", en Arabica 8, fasc. 2, (1961) pág, 182.

${ }^{36}$ Posiblemente préstamo del francés chemise "camisa" (?).

${ }^{37}$ La vía de entrada al dialecto de este préstamo es confusa. Según BARTHÉLEMY, A. Dictionnaire árabe..., pág. 64, el origen es el término francés pantalon y la vía de entrada al dialecto ha sido la lengua turca. Por otro lado, FRAYHA, A. A Dictionary..., pág. 16, indica que procede del italiano pantalone. 
Quiero decir que al final el hijāb no es este pedazo de tela que se pone en la cabeza, que significa que esta persona es retrasada o no retrasada, y no significa que si yo llevo el hijäb eso quiere decir que soy una buena persona o que estoy haciendo algo bueno, no, al final yo lo hago por mí.

O sea, la chica que lleva hijāb no se diferencia en nada de la que no lleva, e incluso no se diferencia en nada a la que va desnuda. Cada uno al final es él y lo que hace. Y el hijāab, hay mucha gente que considera que hay que ponerlo por religión, por la religión islámica, que el hijāb está impuesto para que la mujer no llame la atención, sí, no llame la atención pero ¿para qué? para que ella se proteja a sí misma, a ver... para que nadie débil o enfermo mire a una mujer, la encuentre muy bonita, encuentre su cuerpo descubierto... y vaya él, que no puede hacer cualquier... hacer sexo con nadie, ¿sí? o que tenga ganas de hacer esto, de hacer sexo con alguien, entonces puede que vaya y le haga daño, puede que vaya y la fuerce, ¿bien? ahora los tiempos han cambiado, ¿vale? y hay gente que dice: "Bien, ¿por qué los hombres no se ponen también el hijāb?". Bien, porque él es hombre, no hay nada que llame la atención... al final siempre los hombres son más fuertes que la mujer, o sea, él puede ir y hacer daño a la mujer, la mujer no puede hacer nada.

Y también por encima de ella, también... ¿qué quiero decir? lo olvidé... esto, pero... claro que no es siempre esto. No quiere decir que si la mujer va descubierta los hombres directamente van a mirarla, no. Y el hijäb no significa... esto es lo más lo más importante, el punto más importante del hijāa , el hijāa $b$ no significa que una sólo oculta su pelo, no, si ella deja al descubierto su pelo pero cubre todo su cuerpo o viste ropas que no enseñen mucho esto es mejor de que ella se ponga el hijā $b$ y vista ropa ajustada. El hijāab no es sólo para la cabeza, el hijāb es para todo el cuerpo y al final es una decisión personal, personal para uno mismo. Y prueba de esto es que hay muchas mujeres aquí, mujeres en nuestro país, con mucho éxito que llevan el hija $a b .$. no significa que son retrasadas, no, lo llevan como cualquier otra prenda, como la camiseta, como la manga larga o la media manga, como el pantalón corto o el largo. Esto es al final libertad personal.

Y también la chica que ha elegido no ponerse el hijāb, ella también tiene libertad personal. O sea, lo uno como lo otro, ya está.

\subsection{TEXTO 2. UNA SIRIA A LA ÚLTIMA MODA. NŪR ؟AZĪZ}

/[Nūr, tú vas a la moda ¿no?]

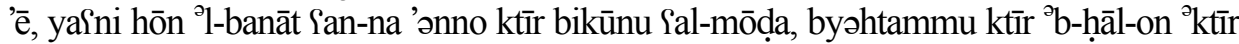

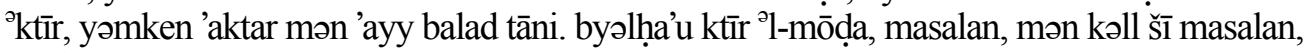

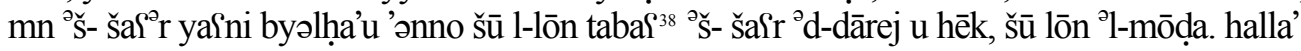

${ }^{38}$ Se trata de la partícula de anexión indirecta utilizada por excelencia en el dialecto de Damasco. Según OULD MOHAMED BABA, A-S. "Las partículas de la anexión indirecta en los dialectos árabes modernos", en Anaquel de Estudios Árabes, 14, (2003), pág. 205.: "</tabißa/ "seguir, pertenecer a". Para otros autores puede provenir de /batå/ (con metátesis)". 
masalan la-nəfrợ 'ənno halla' masalan '1-lōn 'aswad, fa-'ag̉lab '1-banāt fan-na birūhu

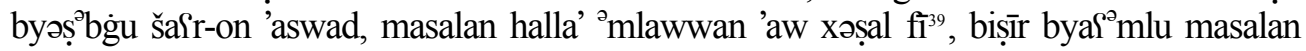
xəșal 'aw halla' masalan 'aḥmar hēk. u 'ənno mənrūḥ Sal-kwā̄ềr ${ }^{40}$ 'ənno ta'rỉban šì marrtēn ${ }^{41}$ bəl-’əsbū؟, fi nās bətrūḥ kəll yōm, bikūn masalan mahwūsīn yâni hadōl, 'ē, bass 'ana

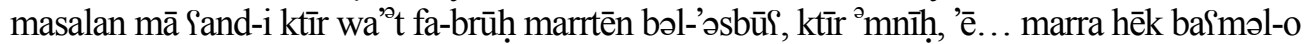
masalan līis ${ }^{42}$, marra ba\{məl-o wēybi ${ }^{43}$ hēk, yaini hasab šũ l-mnāsabe lli fand-i. ktìr masalan

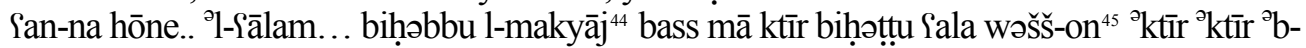

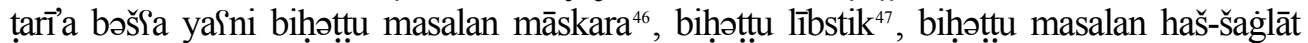
hayy ḥəmra, blāšs ${ }^{48}$ masalan, bass mā bikattru b-țarỉa bəšৎa, byå ${ }^{\circledR}$ mlu ḥawājb-on... masalan 'ana brūḥ marra bəl-’əsbū kamān båmel bēdikūr u mēnikūr ${ }^{49} \mathrm{u}$, 'è... masalan 'ag̉lab ${ }^{~} \mathrm{l}-$ banāt Yan-na masalan hōne biḥıtțu Sala 'aḍafirr-on ${ }^{50}$ 'วnno frēnj ${ }^{51}$ 'aw 'ahmar 'aw bōrdō yåni

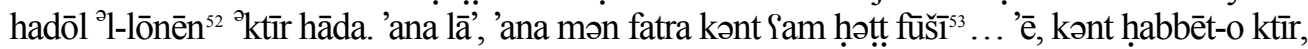

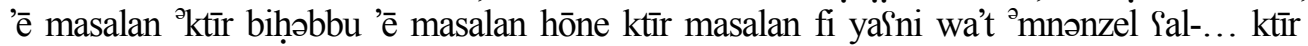
banāt masalan biḩ̧bbu šōbīn ${ }^{54}$ hōn Yan-na bə-šək'l mū maY'ūl, 'ē... mnənzel Yal-... masalan

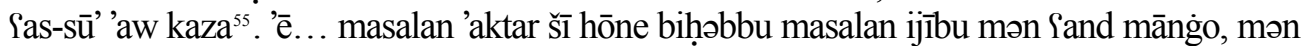
fand mīs sīksti, mən Sand masalan ºtīr maḥallāt.

[¿Y cómo es la ropa que tú te pones?]

[...] 'ē... 'ənno kîf yâni masalan yainni 'ənno fal-mōḍa masalan jīnz $z^{56}$, masalan bəddo ykūn dayye', masalan halla' șahīḥ dārej... masalan hāy hēls ${ }^{57}$ masalan, ${ }^{~} k \uparrow u ̄ b$

${ }^{39}$ El alargamiento de la vocal final se debe al pronombre personal sufijado de tercera persona masculino singular, que queda reducido a un alargamiento vocálico final cuando la palabra termina en vocal.

${ }^{40}$ Préstamo del francés coiffeur con el significado de "peluquera".

${ }^{41}$ Morfema de dual/-ēn/, único para todos los sustantivos en el dialecto de Damasco.

${ }^{42}$ Préstamo no integrado del francés lisse "liso".

${ }^{43}$ Préstamo no integrado del inglés wavy "ondulado".

${ }^{44}$ Préstamo del francés maquillage "maquillaje".

${ }^{45}>$ wajh "cara". Se trata de uno de los pocos casos de asimilación recíproca (/jh/ > /šš $\left./\right)$, donde la consonante $/ \mathrm{h} /$ ha ensordecido a la consonante $/ \mathrm{j} / \mathrm{y}$ ésta a su vez ha prepalatizado a $/ \mathrm{h} /$.

${ }^{46}$ Préstamo no integrado del inglés mascara "máscara de ojos".

${ }^{47}$ Préstamo no integrado del inglés lipstick "pintalabios".

${ }^{48}$ Préstamo no integrado del inglés blush "colorete".

${ }^{49}$ Préstamo del francés manicure "manicura".

${ }^{50} \mathrm{El}$ esquema de plural del ac. 'aFāsil acorta la /ā/ convirtiéndose en 'aFåil . Este fenómeno se produce igualmente en el esquema del ac. maFāsíL que se convierte en 'áFāsíL. Ejemplo: mawāậ̆ (árabe clásico) "temas" $\rightarrow$ mawa đ̣̣ $\uparrow$ (dialecto de Damasco); mašārị̂ (árabe clásico) "proyectos" $\rightarrow$ mašarī $($ dialecto de Damasco).

${ }^{51}$ La informante utilizó esta palabra en inglés: french "francés".

${ }^{52}$ En el dialecto desaparecen los adjetivos demostrativos duales, utilizando en su lugar los plurales.

${ }^{53}$ Préstamo del francés fuchsia "fucsia".

${ }^{54}$ Préstamo del inglés shoping "compras", no integrado.

${ }^{55}$ Del ac. kada. La pérdida de las consonantes interdentales origina el cambio $/ \underline{d} />/ z /$ en los términos considerados como más cultos, para el resto el cambio es $/ \underline{\mathrm{d}} />/ \mathrm{d} /$. Ejemplo: dahab "oro" (árabe clásico) $\rightarrow$ dahab (dialecto de Damasco).

${ }^{56}$ Préstamo del inglés jeans "pantalones vaqueros". 


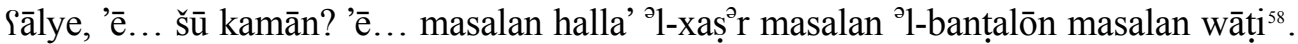
halla' ṣahịḥ dārej fāli w Sarīẹ masalan jīnzāt, bass 'ana mā ḥabbè̀t-a hal-mōọa kəll-a, sahịh Yal-mōạa bass mū bə-haš-šagile mā habbēt-a. 'ē... masalan šū kamān masalan

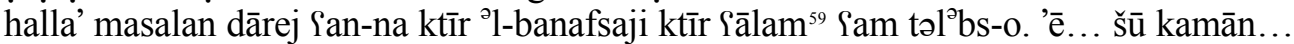

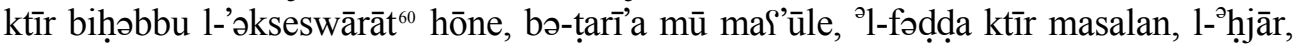

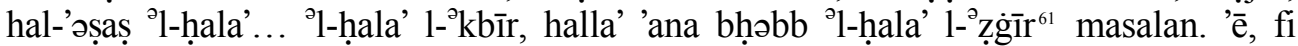

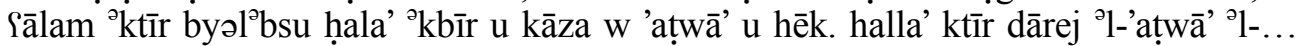
yâni mətl ’ l-fəḍda 'aw bikūn lōn-o fəḍdi 'aw dahabi 'aw šū ma kān, țwāl u kbār yâni

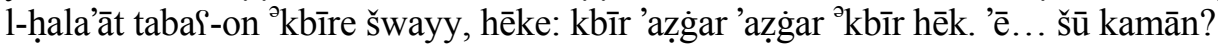

masalan 'ktīr masalan 'ənno biḩəbbu s-sahar, biḩəbbu yâni masalan 'ənno

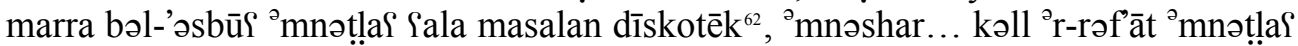

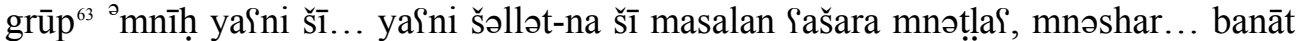

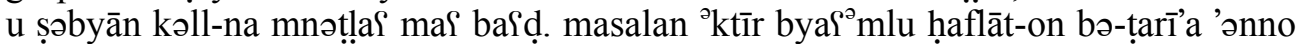
zyāde yaini 'ənno 'afyāa mīlād, hạflāt taxarroj, hafle hēk... kaza wadāi, 'əstə'bāl... ${ }^{2} \mathrm{ktīr}{ }^{\circledR} \mathrm{ktīr}$ mnåmel haflāt yåni.

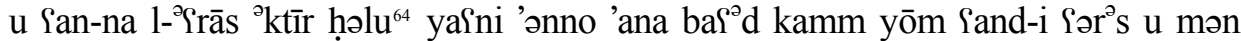

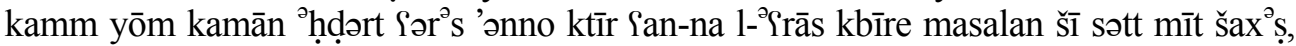

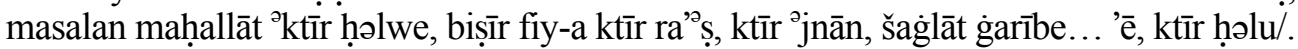

\subsection{TRADUCCIÓN}

[Nūr, tú vas a la moda, ¿no?]

$\mathrm{Si}$, a ver, aquí las chicas van mucho a la moda, se interesan mucho por su aspecto, mucho mucho, quizás más que en cualquier otro país. Siguen mucho la moda, por ejemplo, en todo, por ejemplo, en el pelo, o sea, siguen el color que es el último grito y así, cuál es el color de moda. A ver, por ejemplo, vamos a suponer que ahora por ejemplo es el color negro, pues la mayoría de las chicas aquí van y se tiñen el pelo de

\footnotetext{
${ }^{57}$ Préstamo no integrado del inglés high heels "tacones altos".

${ }^{58}$ De la raíz clásica $\{\mathrm{WT}$ ’ $\}$, con transformación de hamza final en /y/, dando como resultado la raíz dialectal $\{\mathrm{WTTY}\}$.

${ }^{59}$ El sustantivo clásico Sālam "mundo" en el dialecto de Damasco adopta en numerosas ocasiones el significado de "gente".

${ }^{60}$ Préstamo del francés accessoire "accesorios".

${ }^{61}$ El adjetivo clásico șaḡir "pequeño" sufre una serie de modificaciones en el dialecto. En primer lugar la pérdida de la vocal en sílaba inicial al estar seguida de una consonante y de una vocal larga, además presenta una desenfatización de /ṣ/ y la sonorización de la misma, esto es $/ \mathrm{s} />/ \mathrm{s} />/ \mathrm{z} /$.

${ }^{62}$ Préstamo del francés discothèque "discoteca".

${ }^{63}$ Préstamo del inglés group "grupo", no totalmente integrado aunque en la actualidad es muy usado por la población joven que además sigue utilizando los términos árabes šolle y majmū̧a con el mismo significado.

${ }^{64}$ Vocalización de la semivocal /w/ al final de una palabra y precedida de una consonante. Sobre este fenómeno ver NAKHLA, R. Grammaire du dialecte libano-syrien. (Phonétique, Morphologie et Syntaxe). Vol. I: Exposé des règles. Beirut. 1937, pág. 20.
} 
negro, por ejemplo, ahora de colores o con mechas, pues puede que se hagan mechas o por ejemplo rojo, así. Y vamos a la peluquería unas dos veces por semana, hay gente que va todos los días, éstos son fanáticos, pero yo por ejemplo no tengo mucho tiempo así que voy dos veces por semana, está muy bien, sí... una vez, por ejemplo me lo aliso, otra vez me lo rizo, así, depende cual sea la ocasión que tenga. Aquí, por ejemplo, a mucha gente le gusta el maquillaje pero no se pintan de una forma muy muy fea, a ver, se ponen por ejemplo máscara, se ponen pintalabios, se ponen estas cosas, pintalabios, colorete por ejemplo, pero no se exceden de forma fea, se hacen las cejas... por ejemplo, yo voy una vez a la semana también y me hago la pedicura y la manicura y, eh... por ejemplo, la mayoría de las chicas aquí se ponen en las uñas la manicura francesa o rojo o color vino, estos dos colores mucho. Yo no, yo hace tiempo me ponía fucsia... sí, me gustaba mucho, eh... por ejemplo, les gusta mucho... por ejemplo cuando vamos a... a muchas chicas por ejemplo les gusta ir de compras aquí, de manera increíble, eh... vamos a... por ejemplo al mercado y esas cosas. Por ejemplo aquí lo que más les gusta es comprar ${ }^{65}$ de Mango, de Miss Sixty, de muchas tiendas.

\section{[¿Y cómo es la ropa que tú te pones?]}

Eh... ¿que cómo?... a ver por ejemplo, a la moda, por ejemplo los vaqueros, por ejemplo, tienen que ser estrechos, y por ejemplo, ahora lo que está de moda... por ejemplo los tacones altos... eh... qué más... por ejemplo la cintura, el pantalón bajo. A ver, lo que está de moda ahora es lo alto y ancho, por ejemplo los vaqueros, pero a mí no me gusta toda esta moda, voy a la moda pero no con lo que no me gusta. Eh... por ejemplo... qué más, por ejemplo, a ver, aquí está muy de moda el púrpura, mucha gente se lo pone. Eh... que más... les gustan mucho los complementos, de una forma increíble, la plata muchísimo, por ejemplo, las piedras, estas cosas, los pendientes... los pendientes grandes, a ver, a mi me gustan los pendientes pequeños, por ejemplo. Hay mucha gente que lleva pendientes grandes y estas cosas y collares y todo esto. A ver, están muy de moda los collares... como la plata o plateados o dorados o como sean, largos y grandes, sus anillas un poco grandes, así: grande, más pequeño, más pequeño, grande, así. Sí... ¿Qué más?

Por ejemplo, les gusta mucho trasnochar, les gusta por ejemplo... una vez a la semana vamos por ejemplo a la discoteca, trasnochamos... todos los amigos salimos en un buen grupo, unos... o sea, nuestro grupo es de, por ejemplo, unos diez, salimos, trasnochamos... chicas y chicos todos salimos juntos. Por ejemplo, organizan mucho sus fiestas de forma excesiva, o sea, los cumpleaños, fiestas de graduación, una fiesta de esto... alguna despedida o bienvenida... hacemos muchas muchas fiestas.

Y las bodas aquí son muy bonitas, a ver, yo dentro de unos días tengo una boda y hace unos días también fui a una boda, es decir, que las bodas aquí son muy grandes, por ejemplo de seiscientas personas, por ejemplo, lugares muy bonitos, hay mucho baile, muchas locuras, cosas extraordinarias... eh... muy bonito.

${ }^{65}$ Lit.: ijību "traer". 